\title{
The struturing of an Ergonomics Program as a Center of Occupational Health Component in a public health institution
}

\author{
Suzana S. M. Lugão ${ }^{a,}{ }^{*}$, Simone L. S. I. Ricart ${ }^{b}$, Renata M.S. Pinheiro ${ }^{c}$, and Waldney M.Gonçalves ${ }^{d}$ \\ ${ }_{\mathrm{a}, \mathrm{b}, \mathrm{c,d}}$ Equipe de Ergonomia da Coordenação de Saúde do Trabalhador (CST), Diretoria de Recursos Humanos \\ (DIREH), Fundação Oswaldo Cruz (FIOCRUZ),RJ, Brasil
}

\begin{abstract}
This article presents the description and discussion of a pilot project in an ergonomic action developed in a public health institution. This project involves the implantation of an Ergonomics Program (PROERGO) in a department of this institution, guided by a methodology structured on six stages, referenced in the literature by ergonomics authors. The methodology includes the training of workers and the formation of facilitators and multipliers of the ergonomics actions, aiming to the implementation of a cyclical process of actions and the consolidation of an ergonomics culture in the organization. Starting from the results of this experiment we intend to replicate this program model in other departments of the institution and to propose the methodology applied as a strategy of intervention to Occupational Health area.
\end{abstract}

Keywords: Ergonomics Program, Occupational Health, Public Institution

\section{Introduction}

This article has as objective describe an experience of implementing an ergonomics program PROERGO - in a Public Health Institution in Rio de Janeiro.

The ergonomics actions have been developed at this institution since 2001, on the perspective of Occupational Health field, in order to act in line with the principles of surveillance, prevention and health promotion. These principles consist on the foundations of the institutional mission of the organizational Department of Worker's Health - CST.

During 10 years ergonomics assessments of work environments were developed and processes in several sectors, services and departments of the different units that compose the institution in Rio de Janeiro. Over the years the demands for ergonomics actions have been increasing and an effort was initiated in order to respond to the growth of the demands and include a larger number of workers by a new strategy. This strategy is the development of ergonomics programs (PROERGO) in each unit on the organization.

The International Ergonomics Association (IEA) difines Ergonomics as the scientific discipline related to understanding the interactions between humans and other elements or systems, and application of theories, principles, methods and data on projects to optimize the wellbeing human and overall system performance. It focuses on people working activity, on the situation where this occurs as an object and its finality is the transformation to improve this system.

Three major interrelated methodological forms are described in Ergonomics: the analysis of work processes, ergonomic design and ergonomic implement. ${ }^{1}$

Practitioners of ergonomics contribute to the planning, design and evaluation of tasks, jobs, products, environments and systems to make them

\footnotetext{
*Corresponding author: Av. Brasil, 4365- Manguinhos. Pavilhão Carlos Augusto da Silva, sala 208. Rio de Janeiro - RJ. CEP: 21040-900. E-mail: ergonomianustcst@fiocruz.br
} 
compatible with the needs, abilities and limitations of people. $^{2}$

The Ergonomics Program (PROERGO) is "an integrated management of labor, environment and health that combines inner and structure of interventions and the concomitant actions to ergonomic interventions. (...) Have the basic objective of enabling the practice of ergonomics in the company in a permanent, progressive and articulate, instead of the possible, timely and localized work. " 3

The commitment of management, employee involvement, identification and control of ergonomics risks, education and training, in addition to health issues management, are the nuclear elements that converge to the effectiveness of the Ergonomics Program. ${ }^{3}$

In 2010 PROERGO deployment process was initiated as a pilot project in a department of the referred public health institution.

\section{Methodology}

The development of PROERGO was structured in six steps guided by the methodology proposed by Vidal (2002), they are:

Step 1 - Awareness;

Step 2 - Formation of the Action and Decision Groups;

Step 3 - Training;

Step 4 - Assessment of environments and work processes;

Step 5 - Implementation monitoring;

Step 6 - Results evaluation.

The PROERGO pilot project implementation proposed to the department was preceded by a sequence of situations experienced by the ergonomics staff, which are described below:

- Situation 1 - Coming of a demand for Ergonomic Work Analysis (EWA) in an activity work at a sector of the department;

- Situation 2 - Development and conclusion of the EWA, according to the model proposed by Wisner $(1994)^{4}$, which includes: demand analysis and contracts proposal; technical, economic and social enviromental analysis; activities and work situation analysis and return of the results; ergonomic recommendations and validation of intervention and recommendations effectiveness;
- Situation 3 - Coming of demand for Ergonomic Work Analysis in the other sectors of the department;

- Situation 4 - Interest and request from the health technical staff of the department to develop partnership on work with ergonomics staff;

-Situation 5 - Proposal to implement the Ergonomics Program in the department;

- Situation 6 - Regular meetings to structure and concept the PROERGO at this department;

- Situation 7 - PROERGO deployment.

\section{Discussion}

The source of the process for deploying PROERGO occurred from a punctual ergonomic action developed in a specific work activity in a department at the public health institution. Based on the phase, wich of the results and data of the ergonomic avaliation are returned to workers and managers, the last one considered the importance of worker participation in the process of search to improvements at working conditions. From this moment, managers demands other ergonomics assessments for other sectors of the department.

In the middle of this setting, the ergonomics staff from the Occupational Health Coordination has proposed the development of the PROERGO with the following objectives: to promote gradually collective reflection on the working conditions; establishing a culture in ergonomics at the organization; mobilize workers to participate on the ergonomic actions developed inside the departament, establishing partnerships; identify and propose measures to control ergonomic hazards in labor places; to promote improved working conditions in a continuous, systematic and sustainable way, and, finally, to improvement indicators related to the incidence of awayments and complaints related to health.

As for the methodological steps to deploy the PROERGO, it is noteworthy that until now three of the six stages have been developed.

The first step was to raise awareness of the collective of workers and managers on the concepts of ergonomics and ergonomic action. This step was performed four times that contemplated meetings between the ergonomics staff and the workers only, and between managers and ergonomics staff exclusively. The exclusive meeting with the workers were systematized in a week of daily meetings with small groups, using the space created by the 
department's technical to groups discussion of the internal issues. The objective was to use this space to stimulate and verify the participants' interest in discussing issues related to work processes and to integrate the PROERGO Action Group.

The closure of the stage was marked by an awareness workshop entitled "Workshop on Senraising and information in Ergonomics", with a schedule of five hours, included in the "Internal Seminar" held annually in the department. This workshop included all department employees, who make up a total of 90 participants.

The second stage of the methodology consisted of the constitution of the Ergonomics Action Group. The group was formed by 13 workers strategically chosen by the technical staff of the department among those who have expressed interest in participating in the PROERGO. During the awareness stage, the workers could voluntarily sign up to participate in a training and act as facilitators of ergonomic actions in the department. At least one representative from each of the sectors that make up the department was included in the Action Group.

The criterion for the choice of workers who constitute the Action Group of the many subscribers has been decided by the technical staff of the department according to the profile and characteristics of individual workers. We evaluated issues such as representation in the work teams, leadership and ability to teamwork.

The Decision Group for PROERGO was formed by the manager of the Department. It is interesting to note that the management structure of this department consists of only a chief manager, which acts together with a technical team with representatives from each area of the organization. Therefore, the technical team can also be considered as part of the Decision Group. Thus, some members of the Action Group also belong to the Decision Group. We consider this aspect as positive in order to bring next to the Action Group and to the practical experience of the development of the ergonomics action, the members of the decision making sphere in this department.

In the third stage was developed training Ergonomic Action Group. This was organized in eight fortnightly meetings over a period of three months, totaling 44 hours of training including theoretical and practical lessons. The purpose of the training was to provide equalization of knowledge about ergonomics and to facilitate the identification of ergonomic hazards in the environment and work processes.
The fourth stage of this pilot project includes the development of ergonomic actions and it is actually in progress. This step aims to identify and map all work processes of the department by developing a schedule of priorities from the Action Groups and Decision.

The monitoring of actions taken by the Action Group set up the 5th stage of the Program. The intention is that at this time, the ergonomics staff along with the Action and the Decision Groups could verify the process of implementing the changes and verify the results obtained from the changes.

A workshop with an expected annual basis to assess the PROERGO is the 6th and final stage of the proposed methodology.

\section{Conclusion}

At the end of the training process and training of the Action Group, it was found that the professionals that integrates it were able to identify ergonomics risk situations and propose measures of control over the physical, cognitive and organizational features.

It is understood that by employing this methodology the possible to establish a cyclical process of ergonomics actions at this department will be reached, instituting an ergonomics culture at this organization. This contribution aims to stablish the continuous improvement of work processes and the resulting benefits derived from the changes implemented, as regards health, safety and efficiency.

The experience on the development of the proposals methodological stages for a PROERGO in the public health institution, shall meet the characteristics and particularities of each organization. However, it is intended that part of the strategies discussed in this article and can be replicated in other departments of the same organization.

\section{Referências}

[1] Vidal, M. C., 2003, Guia para Análise Ergonômica do Trabalho (AET) na empresa: uma metodologia realista, ordenada e sistematizada. Rio de Janeiro: Editora Virtual Científica

[2] Iida, Itiro, 2005. Ergonomia Projeto e Produção. $2^{\mathrm{a}}$ edição, São Paulo: Edgard Blücher.

[3] Vidal, M. C. Programas de Ergonomia na Empresa como competência imprescindível para a competitividade mundial. Anais Congresso ABERGO - Recife. 2002

[4] Wisner, Alain. A metodologia na ergonomia ontem e hoje. In: A inteligência no Trabalho. São Paulo: Fundacentro, 1994. 